\title{
Recovery from acute kidney injury is a potent predictor of survival and good neurological outcome at discharge after out-of-hospital cardiac arrest: Fact or fiction
}

\author{
Patrick M. Honore, Luc Kugener, Sebastien Redant, Rachid Attou, \\ Andrea Gallerani, David De Bels \\ ICU Department, Centre Hospitalier Universitaire Brugmann, Brussels, Belgium
}

\section{TO THE EDITOR}

We read with great interest the recent paper by Park et al., who conclude that recovery from acute kidney injury (AKI) is a potent predictor of survival and good neurological outcome at discharge after out-of-hospital cardiac arrest (OHCA) ${ }^{\left[{ }^{[1]}\right.}$ We would like to make some comments. According to the authors, we should interpret these results carefully because the characteristics of OHCA patients are significantly different from critical care patients such as those with severe sepsis. ${ }^{[2]}$ Indeed, whole body ischemia and reperfusion lead to post-cardiac arrest syndrome, including brain injury, myocardial dysfunction, systemic ischemia, and reperfusion response. ${ }^{[3]}$ Various factors, including the duration of ischemia, cause of cardiac arrest, OHCA interventions, and the patient's baseline health status, could affect neurological outcomes in OHCA patients. ${ }^{[1-3]}$ We noticed when comparing the two cohorts' non-recovery versus AKI recovery that for AKI non recovery, age $>60$ years was significantly higher $64 \%$ in AKI non-recovery versus $45 \%$ in recovery group ( $P$ value of 0.012$) \cdot .^{[1]}$ Also, the incidence of diabetes mellitus was $35 \%$ in the non-recovery group versus $19 \%$ in the recovery group ( $P$ value of 0.022$)$. Further, the adrenaline dose above $4 \mathrm{mg}$ was $74 \%$ in non-recovery versus $17 \%$ in recovery ( $P$ value of 0.002 ). The cardiopulmonary resuscitation time $>6 \mathrm{~min}$ was $74 \%$ in nonrecovery versus $59 \%$ in recovery $(P$ value of 0.002 ). Lastly, shock was present in $91 \%$ of the non-recovery group versus $67 \%$ of the recovery group ( $P$ value of 0.001 ). Altogether and knowing the retrospective multicenter cohort study design, these five significant risk factors for poor neurological outcome are already enough to explain a bad neurological prognosis even without AKI recovery or not. In a recent study of 1,826 patients with OHCA, after excluding patients with an in-hospital cardiac arrest, a non-shockable rhythm, and no adrenaline administration, ${ }^{[4]}$ it was concluded that among survivors, those who received less than $2 \mathrm{mg}$ of adrenaline had a more favorable neurological outcome than those administered $>3 \mathrm{mg}$ (cerebral performance category [CPC] 1-2 $16.6 \%$ vs. $12.5 \%$, $P=0.004)$. Again, this is a similar finding to the study of Park et al. ${ }^{[1]}$ In another recent trial, the authors concluded that in prolonged OHCA, initial shockable rhythm, age $<65$ years, and witnessed arrest are predictors for neurological intact survival. ${ }^{[5]}$ Again, the presence of comorbidities like age is crucial for good neurological outcome. It stands to reason that the relationship founded by Park between AKI recovery and good neurological outcome might be only a pure association and nothing else. A randomized controlled study is surely warranted to explore further this finding.

\section{Conflict of Interests}

The authors declare no competing interests. 


\section{REFERENCES}

1. Park YS, Choi YH, Oh JH, Cho IS, Cha KC, Choi BS, et al. Recovery from acute kidney injury as a potent predictor of survival and good neurological outcome at discharge after out-of-hospital cardiac arrest. Crit Care 2019; 23: 256.

2. Peters E, Antonelli M, Wittebole X, Nanchal R, Francois B, Sakr Y, et al. A worldwide multicentre evaluation of the influence of deterioration or improvement of acute kidney injury on clinical outcome in critically ill patients with and without sepsis at ICU admission: results from The Intensive Care Over Nations audit. Crit Care 2018; 22: 188.

3. Hassager C, Nagao K, Hildick-Smith D. Out-of-hospital cardiac arrest: inhospital intervention strategies. Lancet 2018; 391: 989-98.
4. Sigal AP, Sandel KM, Buckler DG, Wasser T, Abella BS. Impact of adrenaline dose and timing on out-of-hospital cardiac arrest survival and neurological outcomes. Resuscitation 2019; 139: 182-8.

5. Ahn S, Lee BK, Youn CS, Kim YJ, Sohn CH, Seo DW, et al. Predictors of good neurologic outcome after resuscitation beyond $30 \mathrm{~min}$ in outof-hospital cardiac arrest patients undergoing therapeutic hypothermia. Intern Emerg Med 2018; 13: 413-9.

How to cite this article: Kugener L, Redant S, Attou R, Gallerani A, De Bels $D$. Recovery from acute kidney injury is a potent predictor of survival and good neurological outcome at discharge after out-of-hospital cardiac arrest: Fact or fiction. J Transl Intern Med 2021; 9: 57-8. 